\title{
ASSESSING RISK FOR STRATEGY FORMULATION IN STEEL INDUSTRY THROUGH REAL OPTION ANALYSIS
}

\author{
Farrah Merlinda MUHARAM \\ Universitat Autonoma de Barcelona, Spain
}

\begin{abstract}
While the efficiency of financial systems rests primarily on proper risk assessment and management, real option valuation (ROV) grounds strategic thinking and decision making analysis. Starting with the adoption of ROV in capital budgeting process, risk is assessed in a way so that it can be prevented or exploited or both, creating future options that incorporate uncertainty and provide flexibility. Taking both statements into concrete consideration, this paper analyses the risk faced by SMEs in the steel industry, aiming to exploit it in a different perspective. Despite the fact that the participation of SMEs in this industry is growing, many of them are still facing problems in allocating limited resources, assessing risk and strategic planning - financially or non-financially. ROV is capable to provide solutions to deal with the lack of SMEs strategic management practices by providing general application guidelines on risk assessment for the purpose of strategic planning.
\end{abstract}

KEYWORDS: Real Options, Strategic Formulation, Risk Assessment, SMEs

\section{INTRODUCTION}

Risk is defined by Collins Concise Dictionary \& Thesaurus (2006) as "the possibility of bringing about misfortune or loss" which also bear the same meaning as "danger, hazard, pitfall, peril and uncertainty". Taking this definition into economic perspective, risk is future uncertainty which needs to be managed in order to avoid variety of consequences ranging from negative surprises to permanent loss (Triantis, 2000).

It is important to emphasize risk assessment in managerial activities. Firms manage risks for various reasons. For example, in current conditions where input suppliers hold their reserves to enjoy profits on surging market and higher prices, there is a need to enter into a contract with better terms thus agreed upon a specific price (Triantis, 2000); or face the risk of incurring higher input cost for production in the future. Firms should plan to maintain a steady cash flow so that the risk of falling short of earnings is avoidable (Triantis, 2000). Maintaining a "proper" flow of revenue is also part of tax strategy to avoid the risk of paying higher tax (Chapman, 2006). Reducing variability and volatility of cash flow lead to higher after tax profits. In undertaking new investments, proper risk management will reduce the incidents of decreasing value of investment decisions and reduce the probability of costly external financing on firms' value (Triantis, 2000; Chapman 2006). Early recognition of possible risk facilitates the achievement of optimal investment. Chapman (2006) adds that risk management gives the opportunity to "copy" industry peers to avoid underperforming benchmark and increase firms' value that result in increment of firms' value thus lower the probability of bankruptcy, lead to better access to capital markets and increase debt capacity.

With the various advantages profited from managing risk, apart from being illustrated above, limited number of businesses especially small and medium enterprises (SMEs) are putting serious effort into this activity (Wang, Walker \& Redmond, 2007). Risk management is seen as a sophisticated activity that belongs only to big corporations.

With the emergence of SMEs as a new economic driver for many countries, SMEs' natures of business are not limited to simple and traditional activities anymore. Higher participation of SMEs in many complex activities such as steel industry is noted in Belgium, Indonesia, China and India (Culkin \& Smith, 2000; Sato, 2000; 2009). It flags that SMEs are in great need to practice a proper way of managing risk. Furthermore, with the support of governments' policies in many economic agendas (Abdullah \& Bakar, 2000), SMEs should exploit the opportunity to grow and prosper. Yet, there are questions arise when it comes to managerial approach of risk assessment:

a. How SMEs are able to approach risk from an economic perspectives?

b. How risks observed are integrated into strategic management practices? 
Journal of Global Strategic Management | V. 5 | N. 2 | 2011-December | isma.info | 5-15 | DOI:10.20460/JGSM.2011515794 Proposing to include additional step of real option valuation (ROV) into risk assessment process, this paper aims to answer to above questions. By performing a case study based on stylized facts in first stage steel processing, it hopes to contribute to enrich the literature towards the usage and application of ROV (Trigeorgis, 1993b). The results also propose solutions to SMEs on how risks should be exploited and turned into opportunities, thus able be incorporated into their strategic practices.

This paper is structured as follows. The next section, Section 2 summarizes the development of risk management in capital budgeting and risk management without the attachment onto any financial derivatives. With the introduction of ROV into the assessment process, risks especially those related to operational uncertainties are assessed before being incorporated into the evaluation. Section 3 illustrates the framework of study before analyses of risk management process is conducted in Section 4 . The results are discussed and concluded in section 5 .

\section{LITERATURE REVIEW}

Risk management started to gain attention when Bowman (1980) identifies the "risk-return paradox". According the paradox which based on investors' viewpoint, stocks with greater risk need to offer higher return so that it attracts risk-adverse investors' interest. Yet, Bowman's finding shows totally opposite result. He finds that firms with greater return have actually lower level of risk. This is due to strategic practices which adapt skilful, rigorous and continuous activities of risk management (Bettis, 1983). Since then many development of risk management approaches, processes and tools emerged.

One of the developments includes real options theory which emanates from the seminal article of Black-Sholes and Merton on European and American options in 1973. The key element argued by this theory is the failure of Net Present Value (NPV) to include uncertainty and provide flexibility in pricing up investment. This weakness leads to undervaluation (Trigeorgis, 1993a), difficulties in incorporating investment decision into strategic planning (Bierman, 1988) and very rigid for firms to react to continuously changing environment (Luerhman, 1998; Pogue, 2004). Ross (1995:101) insisted that "For most investments, the usefulness of the NPV rule is severely limited".

Real options adapt financial options parameters which based on operational activities (Kogut, 1991). Real options are relevant to strategists as all decisions are made based on the ability of firms to allocate resources that fit into strategic mission (Bowman \& Hurry, 1993). Options also grant the "preferential access to future opportunity" (Bowman \& Hurry, 1993: 762). Furthermore, the beauty of real options is it includes both the options of undertaking activities or acquiring resources (Sanchez, 1993). These advantages are quantified, providing quantitative intuition for decision making process (Luerhman, 1998).

With uncertainty and flexibility being incorporated into investment evaluation and strategic planning, managers hold the ability to select an outcome only if it is favourable (McGrath, 1997). It is seen as a risk management tool because of the ability to limit negatives outcomes (Bookstaber, 1981; Bowman \& Hurry, 1993; Sanchez, 1993) which are consistent with the aim of risk management (Triantis, 2000; Chapman, 2006).

Real options allow a subtle different understanding between corporate investments and risk (Bowman \& Hurry, 1993; Sanchez, 1993; Trigeorgis, 1993; McGrath, 1999). The method of application varies, to highlight some of it: from quantitative approaches applied in capital budgeting (Brennan \& Schwartz, 1985; Trigeorgis, 1993a,b; Kellogg \& Charnes, 2000) to more qualitative approaches such as in measuring value creation and strategic planning (Luerhman, 1998; Amram \& Kulatilaka, 2000; Smit \& Trigeorgis, 2006), evaluating corporate social responsibility (Kanter, 1999), risk management (Bowman and Hurry, 1993; Miller and Reuer, 1996) including the preparation of contingency plan (Rogers, Gupta and Maranas, 2003).

\section{METHODOLOGY}

The research conducted in this study follows a stylized fact case study approach, similar to other studies in the field of real options, such as Brennan and Schwartz (1985), Dixit \& Pindyck (1994) and Trigeorgis (1996), in the case of natural resource activities. This approach requires of the construction of a base case with various sources of information representative in a worldwide scenario. The analysis adapts the general risk management process by Chapman (2006). The original steps of this process begin with analysing business and its environment. Next, risks are identified and assessed before formulating strategies. According to Total Model Value by Boer (2002:76), risks affect economic and strategic capital. So, it is suggested that apart from Chapman's process, another step of valuation 
Journal of Global Strategic Management | V. 5 | N. 2 | 2011-December | isma.info | 5-15 | DOI:10.20460/JGSM.2011515794 should be included to provide more quantitative intuition in risk management. As a result, a comprehensive risk management process is derived (refer to Figure 1).

\section{Figure 1: Risk Management Cycle (Source: Own design)}

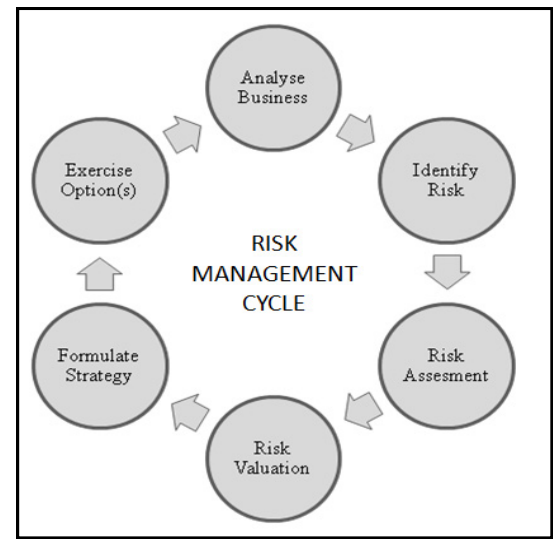

The process is a cyclical process as to suit constantly changing environment. It starts with analysing the business characteristics: strength, weaknesses, opportunity and threats (SWOT) - the mostly applied strategic assessment tool. Next, relevant risk exposures are identified. Each risk is assessed individually and collectively before been measured and valued according to ROV method. The valuation process applied in this study follows a methodology of log-transformed binomial lattice approach developed by Trigeorgis (1991). Calculations are performed using DerivaGem (Hull, 2010). The values are later added to traditional NPV for more meaningful value. The result, term as Enlarged Net Present Value, incorporates uncertainties i.e. in this case - risks; and provide flexibility (Trigeorgis, 1993a) as per equation 1 .

$$
\text { Enlarged (or Strategic) NPV or ENPV }=[\text { NPV + Real Option(s) }]
$$

Later, strategy is formulated to suit firms' interest and mission. When uncertainty becomes plain into view and options are approaching its expiry, firms will choose the best options to be exercised. The cycle will restart after this and constantly proceeds to react to the continuously changing environment.

\section{ANALYSES}

Based on the framework drawn in Section 3, this section analyses the process of risk management from Step 1: Analysing Business Characteristics of the new investment in mini-mill first stage steel processing, until Step 4: Risk Valuation. This section aims to demonstrate how ROV is feasible and practicable to manage risk, taking an example of SMEs' activity in mini-mill smelting project in first stage processing of steel.

Mini-mill approach required low specific investment that attracts new comers (Bonmo, 1998), which supports the recent growth of SMEs' participation in steel industry (Culkin \& Smith, 2000). Production system of mini mill is able to reduce man hours per tonne by minimum $60 \%$, giving greater flexibility on the process and has lower impact on the environment. As the plant is small in scale, it has the possibility to be located near steel users' plant. Many technical advantages of this approach such as replacing the use of coke ovens with COREX process from VAI, thin slab technology for hot strip production including continuous linking of downstream pickling and cold rolling makes mini-mills more preferable among investors.

\section{Business Analysis and Case Background}

Let say, there is a new proposal of building up an iron smelting plan based on new process innovation, mini-mill iron smelting. The investment requires $€ 10$ million, $€ 6$ million in $t_{0}$ and $€ 4$ in $t_{1}$, i.e, $€ 9.81$ million discounted at 5\%. By investing this amount, the firm will have a mini-mill plant with capacity of producing 182000 tons per year. However, due to Kyoto Protocol, the plant is allowed to produce only up to $75 \%$ of its capacity in order to maintain emission and effluent at minimum level. If the levels of emission and effluent exceed the allowable levels, the firm will be penalized. 
Journal of Global Strategic Management | V. 5 | N. 2 | 2011-December | isma.info | 5-15 | DOI:10.20460/JGSM.2011515794

Table 2: Net cash flow calculation during operation period ( $€$ in millions)

\begin{tabular}{|c|c|r|r|r|r|}
\hline Year & $\begin{array}{c}\text { Production } \\
\text { Rate (\%) }\end{array}$ & Gross Revenue & Fixed Cost & Variable Cost & $\begin{array}{c}\text { Net Cash flows } \\
(\boldsymbol{k}=\mathbf{1 2 \%})\end{array}$ \\
\hline 2 & 14.8 & 8.19 & 2 & 6.825 & $(0.635)$ \\
\hline 3 & 45 & 24.57 & 2 & 20.475 & 2.095 \\
\hline 4 & 75 & 40.95 & 4 & 34.125 & 2.825 \\
\hline 5 & 75 & 40.95 & 4 & 34.125 & 2.825 \\
\hline 6 & 75 & 40.95 & 4 & 34.125 & 2.825 \\
\hline 7 & 75 & 40.95 & 4 & 34.125 & 2.825 \\
\hline 8 & 75 & 40.95 & 4 & 34.125 & 2.825 \\
\hline 9 & 75 & 40.95 & 4 & 34.125 & 2.825 \\
\hline $\boldsymbol{V}$ & & & & & $\mathbf{9 . 2 5}$ \\
\hline
\end{tabular}

Figure 2: Investment project with expected option of deferring investment, cancellation during construction, expansion and abandonment

(Source: Own design)

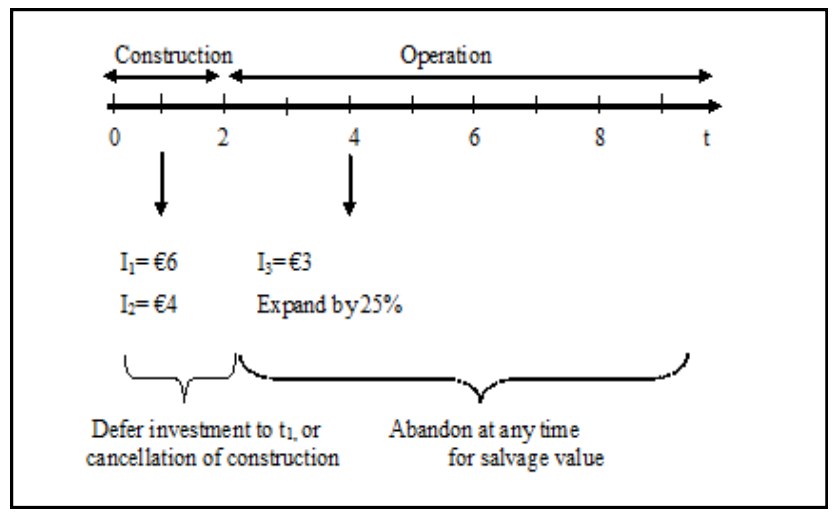

Net cash flows are calculated by extracting all fixed costs and variable costs from gross revenue. For production rate below $50 \%$, fixed cost is $€ 2$ million, and for above $50 \%$ it becomes $€ 4$ million. Table 2 shows the detailed calculations to reach the net cash flows of $V$. The risk-free interest rate is $5 \%$ (continuously compounded $4.879016 \%$ ) and the average adjusted-risk rate is $12 \%$. Average volatility of output prices is $30 \%$. The expected project life is estimated to be 10 years, including two years of construction period. The project is summarized in Figure 2.

With $V$ of $€ 9.25$ million and $I$ of $€ 9.81$ million, the $N P V$ of the project following traditional approach is $€-0.56$ million (negative $N P V$ ). Later, the amount of $N P V$ will be incorporated with ROV to derive at $E N P V$.

\section{Risk Identification}

In this section, risks identified are relevant to the above investment and mostly related to operational activities. Uncertainty is hedged with options rather than using derivatives in financial markets. In short, the possibility of hedging with derivatives is totally disregarded in this study.

Steel industry is highly concerned about the risk of operational hazard like explosion, fire and radioactive contamination especially when it comes to producing as mini-mill plant (Schütz, 2003). Explosion and fire are caused by incidents in furnaces that involve oxygen and highly flammable materials used in heat production. Mishandling of ferrous scraps such as CS 137 and CO 60 may result in radioactive contamination thus incur expensive cleaning cost if happen. 
Journal of Global Strategic Management | V. 5 | N. 2 | 2011-December | isma.info | 5-15 | DOI:10.20460/JGSM.2011515794

The other type of steel industrial risks is less serious but more complicated to deal with - business interruption risk. The first interruption is fluctuation in price of inputs and outputs. Input prices is controlled by major producers and adapted by other small miners as benchmark (Bilous \& Hon, 2004; Robertson, 2008), while outputs are traded in terminal exchange market like London Metal Exchange (LME) and Commodities Exchange New York (COMEX), resulting in little influence for steel producers to control raw material cost and revenue.

As the business is involving in hazardous activities, there is usually higher requirement to be followed and certified causing additional interruptions of legal, taxation and environmental regulation. Steel industry has to compile with many and complex environmental law imposed that nowadays become more and more critical such as awareness to Kyoto Protocol. Tax regime is also continuously changing depending on government interest and current economic situation.

Technical risk is also an interruption which due to obsolesce of technology regardless in line with process and production, hazard prevention or business management. With competition getting stiff, evolutions in technical aspects have been developed to overcome pollution, reduce production cost and improve product quality. Therefore, for a business to survive in this industry, awareness in such development is essential. Finally, the project is also exposed to financial risks when it comes to debt and borrowing cost interest rates and currency exchange risks.

\section{Risk Assessment}

Based on the above risks identified, several precautionary steps to overcome risks have been identified and established by creating four types of real options. The options are option to defer investment, option to cancel investment, option to expand investment and option to abandon investment for salvage value.

Option to defer (Tourinho, 1979; McDonald \& Siegal, 1986; Paddock, Siegel \& Smith, 1988), is valued as an American call. Project initiation may be delayed to next year, $t_{l}$. The projected net cash flows will remain static but the cost of investment will increase by $5 \%$.

Option to cancel during construction is valued as a compound option of a call on a put (Cortazar \& Schwartz, 1993). With this option, construction can be cancelled at any time without any penalty. The firm might earn any invested amount, being discounted at the adjusted-risk rate of $12 \%$. Once cancelled, the project cannot be deferred, expanded or abandoned.

Option to expand (Brennan \& Schwartz, 1985; McDonald \& Siegal, 1985; Pindyck, 1988; Myers \& Majd, 1990) is valued as a European call. At year $t_{4}$ the firm has the opportunity to increase capacity by $25 \%$ without being penalized for polluting the environment according to the Kyoto protocol. The expansion activity includes improvement in process innovation, up-to-date hazard prevention equipment and upkeep with technical advancement.

Option to abandon is valued as an American dividend paying put (Myer and Majd, 1990). At any time the project can be abandoned for alternative use and enjoy a salvage value of, in principle, $50 \%$ of accumulated capital outlays net of $10 \%$ average annual depreciation, being discounted at adjusted-risk rate of $12 \%$. Table 3 summarizes the purpose of these options. 
Table 3: Types and Purpose of Options

\begin{tabular}{|l|l|}
\hline Types of Option & \multicolumn{1}{c|}{ Purpose } \\
\hline Deferral & $\begin{array}{l}\text { - To deal with ex treme fluctuation price in input and output } \\
\text { prices and wait until uncertainty becomes plain in view. }\end{array}$ \\
- To hold investment so that information on latest environmental \\
concerns issues is evident. \\
- To plan for better tax planning so that able to benefit from tax \\
incentives or to reduce tax rate imposed on heavyhazardous \\
activities.
\end{tabular}

Figure 4: Combination of options for the investment according to the proposed sequence (Source: Own design)

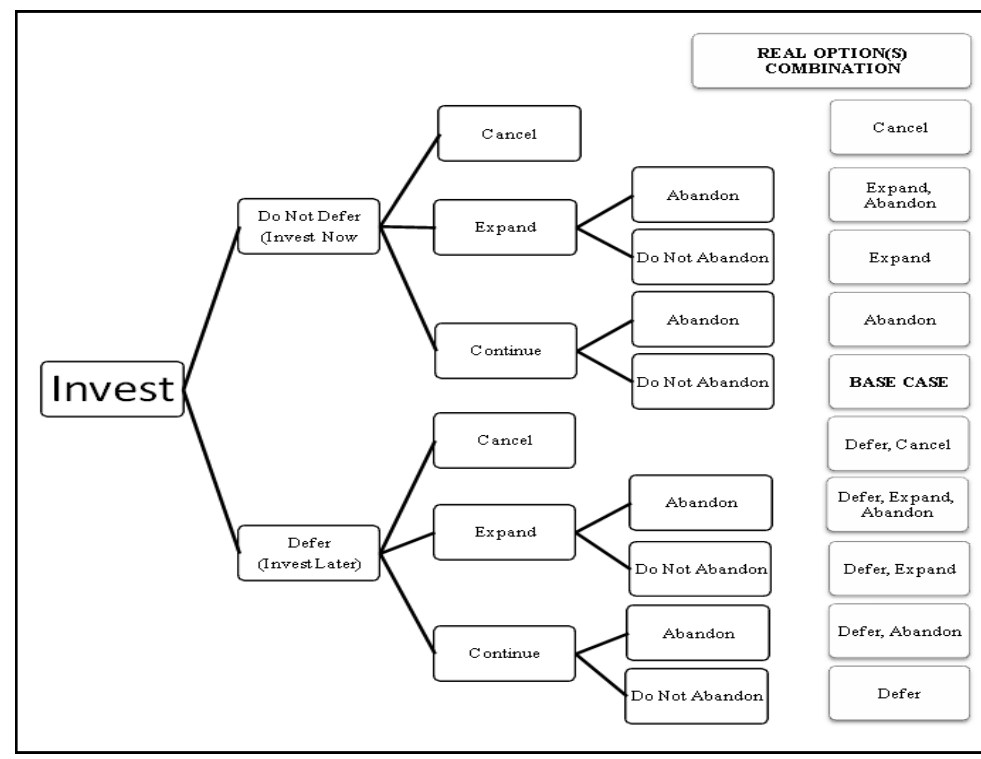

Besides these four individual options, there is possibility of two or more options being combined together as a portfolio. It is crucial to analyse the sequence of options in order to identify any possibility of combining several real options embedded in the nature of an investment project. Smit (1997), for example, has identified the stages in petroleum concession project before valuing it.

For example, from the base case, first, the firm has an option whether to invest now or defer investment. Later, by choosing an option to invest, it opens up to more options. After investment is taken, the firm may choose to cancel it during construction. However, by exercising this option, it closes the opportunity of incorporating other options later. If construction proceeds, investment has the options to expand and/or abandon in later time. Figure 4 shows possible option combinations for the investment according to the sequence proposed. 


\section{Risk Valuation}

The next step performed in this analysis is to value risks which have been incorporated into options using ROV and integrate it into evaluation of project investment. The options are valued individually and collectively as combinations of several options using DerivaGem. The results of valuation are presented in Table 4.

\section{Table 4: Values of options, ENPV and interactions ( $€$ in millions)}

\begin{tabular}{|c|c|c|c|}
\hline Item & Value of Option & $E N P V$ & Interaction $^{2}$ \\
\hline \multicolumn{4}{|l|}{ Individual option ${ }^{3}$} \\
\hline Defer & 1.48 & 0.92 & \multirow{4}{*}{ Not Applicable } \\
\hline Cancel & 0.17 & -0.39 & \\
\hline Abandon & 1.17 & 0.61 & \\
\hline Expand & 3.22 & & \\
\hline \multicolumn{4}{|l|}{ Value with two real options ${ }^{2}$} \\
\hline Defer and cance1 & 0.23 & -0.33 & -1.42 \\
\hline Defer and expand & 2.12 & 1.56 & -2.58 \\
\hline Defer and abandon & 1.63 & 1.07 & -1.58 \\
\hline Expand and aband on & 1.81 & 1.25 & -2.58 \\
\hline \multicolumn{4}{|l|}{ Valve with three real options ${ }^{d}$} \\
\hline Defer, expand and abandon & 2.37 & 1.81 & -4.14 \\
\hline \multicolumn{4}{|c|}{$\begin{array}{l}\text { The value of the combined options minus the sum of separate values i.e. (defer and expand) - } \\
\text { (defer +expand). } \\
\text { "Refer to Append ix A1 - A4 for details. } \\
\text { " Refer to Appendix A } 5 \text { - A8 for details. } \\
\text { "Refer to Append ix A.9 for details. }\end{array}$} \\
\hline
\end{tabular}

\section{DISCUSSION AND CONCLUSION}

With the capability of real options evaluating investment with incorporation of uncertainties and provision of flexibility, it is possible to integrate risk in strategic planning. Risk and flexibility are translated by providing opportunity for managers to defer, cancel, expand and abandon investment (Triantis, 2000). It is important to for managers to understand that by deferring commitment under uncertainty can help firms to avoid losses and enhance firms' value.

Managing risk using ROV as a tool starts with analysing business characteristics. Risks are identified and assessed before being valued. The results obtained from these steps are taken as a benchmark in strategy formulation. Once uncertainties are clearer and plain, managers will choose the best strategy to be exercised that suit firms' interest. After an option is exercised, the whole process has to be performed again so that additional/new risks are identified, assessed and valued before a new set of strategic planning is formulated. This process will continue along project life span over time.

The advantages of ROV are higher compared to financial hedging as real options open up more opportunity. In some cases, risk hedging is only possible with real options especially if uncertainties are related to technical aspects, competitiveness issue, legal/taxation regulations and fluctuation in demand. Projects back up with financial hedging contracts in currency exchange or interest rates would be more secure with the complementary of real options.

ROV included in risk management activities helps firm minimising risks and maximise firm value as proved against the risk paradox (Bowman, 1980). Strategic practices which adapt skilful, rigorous and continuous activities of risk management allow firms to enjoy higher profits (Bettis, 1983) and ROV is seen as a highly potential tool for this purpose. Real options is obviously capable as risk management tool. With high potential of free cost in most of the cases, or lower in any cost anticipated in application of financial derivatives for hedging, ROV promises a cheap tool that perfectly suit SMEs limited budget. 


\section{APPENDICES}

Appendix A1. Deferral Option - Figures and Calculation

$V=€ 9.25$ million $\quad K=€ 10.5$ million $\quad$ Option price $=€ 1.485$ million $\quad E N P V=€ 0.925$ million

Appendix A2. Cancellation Option- Figures and Calculation

$V=€ 9.25$ million $\quad K_{C l}=6(50 \%)=€ 3$ million $\quad K_{C N}=K_{C l}+[4(50 \%)] / 1.12=€ 4.79$ million

Option price $=€ 0.17$ million $\quad E N P V=€-0.56$ million $+€ 0.17$ million $=€-0.39$ million (negative ENPV)

Appendix A4. Abandonment- Figures and Calculation

$V=\mathrm{K}$ discounted at $12 \%=€ 4.435$ million $\quad K=€ 5$ million $\quad$ Option value $=€ 1.17$ million

$E N P V=€-0.56+€ 1.17=€ 0.61$ million

Appendix A3. Expansion Option - Figures and Calculation

$V=€ 5.21$ million

Additional investment, $K_{A}=€ 3$ million $/(1.05)=€ 2.47$ million

Option value $=€ 3.22$ million $\quad E N P V=€-0.56$ million $+€ 3.22$ million $=€ 2.66$ million

Table A3-1: Revenue $(V)$ of expansion option - gross and discounted ( $€$ in millions)

\begin{tabular}{|c|c|c|c|c|}
\hline Year & $\begin{array}{c}\text { Additional } \\
\text { Gross Revenue }\end{array}$ & $\begin{array}{c}\text { Less: Addirional } \\
\text { Variable Cost }\end{array}$ & $\begin{array}{c}\text { Additional Net } \\
\text { Cash Flows }\end{array}$ & $\begin{array}{c}\text { Additional Discounted } \\
\text { Cash Flows }\end{array}$ \\
\hline 5 & 13.65 & 11.375 & 2.275 & 1.291 \\
\hline 6 & 13.65 & 11.375 & 2.275 & 1.153 \\
\hline 7 & 13.65 & 11.375 & 2.275 & 1.029 \\
\hline 8 & 13.65 & 11.375 & 2.275 & 0.919 \\
\hline 9 & 13.65 & 11.375 & 2.275 & 0.820 \\
\hline Total $V$ & & & & 5.212 \\
\hline
\end{tabular}

Appendix A5. Deferral and cancellation- Figures and Calculation

$V=€ 9.8$ million $\quad K_{C l}=€ 2.8$ million $\quad K_{C N}=€ 4.5$ million

Option price $=€ 0.23$ million.

$E N P V=€-0.56$ million $+€ 0.23$ million $=€-0.33$ million (negative ENPV)

Appendix A6. Deferral and expansion- Figures and Calculation

$V=€ 3.92$ million $K=€ 2.4$ million Option value $=€ 2.12$ million

$E N P V=€-0.56+€ 2.12=€ 1.56$ million

Appendix A7. Deferral and abandonment- Figures and Calculation

$I=€ 10.5$ million $\quad V=$ discounted depreciation at $12 \%=€ 3.82$ million

$K=50 \%$ of $\mathrm{I}=€ 5.25$ million $\quad$ Option value $=€ 1.63$ million $\quad E N P V=€-0.56+€ 1.63=€ 1.07$ million

Appendix A8. Expansion and abandonment- Figures and Calculation $V=€ 5.124$ million $K=50 \%$ of Investment $=€ 5$ million $\quad$ Option value $=€ 1.81$ million $E N P V=€-0.56+€ 1.81=€ 1.25$ million

Appendix A9. Deferral, expansion and abandonment- Figures and Calculation $V=€ 4.541$ million $K=€ 6.825$ million Option value $=€ 2.37$ million $E N P V=€-0.56+€ 2.37=€ 1.81$ million 


\section{REFERENCES}

Abdullah, M.A. and Bakar, M.I. (eds.) (2000), Small and Medium Enterprises in Asian Pacific Countries-Volume 1: Roles and Issues, Nova Science Publishers Inc, Huntington, NY, 3-14.

Amram, M. and Kulatilaka, N. (2000), 'Strategy and Shareholder Value Creation: The Real Options Frontier', Journal of Applied Corporate Finance, 15 (2): 8-21.

Bettis, R. A. (1983), 'Modern Financial Theory, Corporate Strategy, and Public Policy: Three Conundrums', Academy of Management Review 8, 405-414.

Bierman, H. (1988), Implementing Capital Budgeting Techniques, revised edition. Cambridge.

Bilous, J. and Hon, K. (2004), North American Steel Industry Study, Toronto, DBRS

Black, F. and Scholes, M. (1973), 'The Pricing of Options and Corporate Liabilities', Journal of Political Economy, 3: 637-659.

Boer, F. P. (2002), The Real Options Solution: Finding Total Value in a High-Risk World, John Wiley \& Sons, NY.

Bonmo, F (1998), 'Summary: Technological Innovation' in “The Steel Industry in the New Millennium”, Ranieri, R \& Aylen, J (Eds.), Maney Publishing.

Bookstaber, R. M. (1981), Option Pricing and Strategies in Investing, Addison-Wesley Publishing Company, Reading, MA.

Bowman, E. H. (1980), ‘A Risk/Return Paradox for Strategic Management', Sloan Management Review 21(3), 17-31.

Bowman, E. H. and Hurry, D. (1993), 'Strategy through the Option Lens: An Integrated View of Resource Investments and the Incremental-choice Process', Academy of Management Review 18(4), 760 -782 .

Brennan, M. and Schwartz, E. (1985), 'Evaluating Natural Resource Investments', Journal of Business, 58(2): 135-157.

Chapman, R. (2006), 'Simple Tools and Techniques for Enterprise Risk Management', John Wiley \& Sons, West Sussex.

Collins Concise Dictionary \& Thesaurus (2006) HarperCollins.

Cortazar, G. and Schwartz, E. (1993), 'A Compound Option Model of Production and Intermediate Inventories', Journal of Business, 66(4): 517-540.

Culkin, N. and Smith, D. (2000), 'An Emotional Business: A Guide to Understanding the Motivations of Small Business Decision Takers', Qualitative Market Research: An International Journal, 3(3): 145 -157 .

Dean, J. (1951), Capital Budgeting, New York, NY, Columbia University Press.

Dixit, A. K., and Pindyck, R. S. (1994), Investment under Uncertainty, Princeton, NJ: Princeton University Press.

Grenadier, S.R. and Weiss, A.M. (1997), 'Investment in Technological Innovations: An Option Pricing Approach', Journal of Financial Economics, 44(3): 397-416.

Hayes, R. and Abernathy, W. (1980). 'Managing Our Way to Economic Decline', Harvard Business Review, July-August, 66-77.

Hayes, R. and Garvin, D. (1982). 'Managing as if Tomorrow Mattered', Harvard Business Review, May-June, 71-79.

Hull, J. (2009), 'Options, Futures and Other Derivatives', $7^{\text {th }}$ edition. Pearson Prentice-Hall, Upper Saddle River, New Jersey.

Kanter R. M. (1999), 'From Spare Change to Real Change', Harvard Business Review 77(3): 122132.

Kellogg, D. and Charnes, J.M. (2000), 'Real-options Valuation for a Biotechnology Company', Financial Analyst Journal, May/June, 76-84. 
Journal of Global Strategic Management | V. 5 | N. 2 | 2011-December | isma.info | 5-15 | DOI:10.20460/JGSM.2011515794 Kester, W. C. (1984), 'Today's Option for Tomorrow's Growth', Harvard Business Review, MarchApril, 153-160.

Kogut, B. (1991), 'Joint Ventures and the Option to Expand and Acquire', Management Science 37 (1): 19-33.

Kulatilaka, N. and Trigeorgis, L. (1994), 'The General Flexibility to Switch: Real Options Revisited', International Journal of Finance, 6 (2): 776-798.

Luerhman, T.A. (1998), 'Strategy as a Portfolio of Real Options', Harvard Business Review, September-October, 89-99.

Majd, S. \& Pindyck, R. (1987), 'Time to Build, Option Value, and Investment Decisions', Journal of Financial Economics, 18(1): 7-27.

McDonald, R. and Siegel, D. (1985), 'Investment of the Firms When There is an Option to Shut Down', International Economic Review, 26(2): 331-349.

McDonald, R. and Siegel, D. (1986), 'The Value of Waiting to Invest', Quarterly Journal of Economics, 101(4): 707-727.

McGrath, R. G. (1997), 'A Real Options Logic for Initiating Technology Positioning Investments', Academy of Management Review 22(4): 974-996.

McGrath, R. G. (1999), 'Falling Forward: Real Options Reasoning and Entrepreneurial Failure', Academy of Management Review 24(1): 13-30.

McGrath, R.G. and Nerkar, N. (2004), 'Real Options Reasoning and a New Look at the R\&D Investment Strategies of Pharmaceutical Firms', Strategic Management Journal, 25: 1-21.

Merton, R.C. (1973). 'The Theory of Rational Option Pricing', Bell Journal of Economics and Management Science, 4(1): 141-183.

Miller, K. and Reuer, J. (1996), 'Measuring Organizational Downside Risk', Strategic Management Journal 17: 671-691.

Myers, S. (1984). 'Finance Theory and Financial Strategy', Interfaces, 14(1): 126-137; reprinted in Midlands Corporate Finance Journal, Spring 1987, 6-13.

Myer, S.C. and Majd, S. (1990), 'Abandonment and Project Life', Advances in Futures and Options Research, 4: 1-21.

Paddock, J. L., Siegel, D.R. and Smith, J.L. (1988), 'Option Valuation of Claims on Real Assets: The Case of Offshore Petroleum Leases', The Quarterly Journal of Economics, 103(3): 479-508.

Pogue, M. (2004), 'Investment Appraisal: A New Approach', Managerial Auditing Journal, 19(4): 565-570.

Robertson, D. (2008), 'Consumers Will Pay as Iron Ore Price Rise Hits Cost of Steel', The Times, February 19.

Rogers, M., Gupta, A. and Maranas, C. (2003), 'Risk Management in Real Options Based Pharmaceutical Portfolio Planning', Proceeding Foundations of Computer-Aided Process Operation (FOCAPO), January 12-15, 2003, Coral Springs, Florida.

Ross, S.A. (1995), 'Uses, Abuses, and Alternatives to the Net-Present-Value Rule', Financial Management, 24(3): 96-102.

Sanchez, R. (1993), 'Strategic Flexibility, Firm Organization, and Managerial work in Dynamic Markets: A Strategic-options Perspective', Advances in Strategic Management 9: 251-291.

Sato, H. (2000), 'How did the Crisis Affect Small and Medium-Sized Enterprises? From a Field of Study of the Metal-Working Industry in Java', The Developing Economies, 38(4): 572-595.

Sato, H. (2009), 'The Iron and Steel Industry in Asia: Development and Restructuring', IDE Discussion Paper, No. 210. Japan: Institute of Developing Economies.

Schütz, D (2003), 'Steel Industry Risks', Regards, 6, May 2003, 1-3.

Schwartz, E. and Moon, M. (2000), 'Rational Pricing of Internet Companies', Financial Analyst Journal, May/June, 62-75. 
Journal of Global Strategic Management | V. 5 | N. 2 | 2011-December | isma.info | 5-15 | DOI:10.20460/JGSM.2011515794 Smit, H.T.J. (1997), "Investment Analysis of Offshore Concessions in The Netherlands', Financial Management, 26(2): 5-17.

Smit H.T.J. and Trigeorgis, L. (2006), 'Strategic Planning: Valuing and Managing Portfolios of Real Options', R\&D Management, 36(4): 403-419.

Tourinho, O. (1979), 'The Option Value of Reserves of Natural Resources', Working Paper 94, Berkeley: University of California.

Triantis, A. (2000), 'Real Options and Corporate Risk Management', Journal of Applied Corporate Finance, 13(2): 64-73.

Trigeorgis, L. (1990), ‘A Real Options Application in Natural Resource Investments', Advances in Futures and Options Research, 4: 153-164.

Trigeorgis, L. (1991). 'A Log Transformed Binomial Numerical Analysis Method for Valuing Complex Multi-option Investment', Journal of Financial and Quantitative Analysis, 26: 309-326.

Trigeorgis, L. (1993a), 'The Nature of Option Interactions and the Valuation of Investments with Multiple Real Options', Journal of Financial and Quantitative Analysis 28(1): 1-20.

Trigeorgis, L. (1993b), ' Real Options and Interaction with Financial Flexibility', Financial Management, 4(3): 202-224.

Trigeorgis, L. (1996), Real Options: Managerial Flexibility and Strategy in Resource Allocation. Cambridge, MA: MIT Press.

Wang, C., Walker, E. and Redmond, J. (2007), 'Explaining the Lack of Strategic Planning in SMEs: The Importance of Owner Motivation', International Journal of Organisational Behaviour, 12(1): 116.

Weston, J. F. and Brigham, E. F. (1981), Managerial Finance, Dryden Press, Hinsdale, IL.

Willigers, B.J.A. and Hansen, T.L. (2008), 'Project Valuation in the Pharmaceutical Industry: A Comparison of Least-squares Monte Carlo Real Option Valuation and Conventional Approaches', R\&D Management, 38(5): 520-537. 